\title{
The effect of CPAP treatment for obstructive sleep apnea on asthma control-study limitations
}

\author{
J. Cravo ${ }^{1}$ - A. C. Pazarli $^{2}$ - A. M. Esquinas ${ }^{3}$
}

Received: 10 May 2016 /Revised: 15 May 2016 / Accepted: 12 July 2016 /Published online: 20 July 2016

(C) Springer-Verlag Berlin Heidelberg 2016

To the editor,

We were very interested in an article recently published entitled "Long-term CPAP treatment improves asthma control in patients with asthma and obstructive sleep apnea" by Kauppi et al. in your journal. We congratulate the authors for their original study, which may develop new ideas for the treatment of asthma in patients with this pathological specificity, which demonstrated that treatment with long duration of CPAP had a positive effect in relieving the symptoms of asthma in patients with a history of asthma and sleep apnea [1]. On the other hand, we have a few remarks for the aforementioned article.

First, the patients were diagnosed with sleep apnea by using polygraphy rather than polysomnography (PSG). However, polygraphy has some limitations in the classification of sleep apnea such as lower sensitivity versus PSG and an increased number of false negatives. Second, bilevel positive airway pressure (BiPAP) is recommended in patients with obesity hypoventilation syndrome, and asthma and obesity history [2]. Nonetheless, the authors recommended automated continuous positive airway pressure (CPAP) and the text lacks

J. Cravo

jcravo87@gmail.com

1 Serviço de Pneumologia A, Centro Hospitalar e Universitário de Coimbra, Praceta Prof. Mota Pinto, 3000-075 Coimbra, Portugal

2 Department of Chest Diseases, Elbistan State Hospital, Kahramanmaraş, Turkey

3 Intensive Care and Non Invasive Ventilatory Unit, Hospital Morales Meseguer, Murcia, Spain data on whether the patients have obesity hypoventilation syndrome or not. Third, we wonder to what extent patients' responses are reliable, especially those being treated with CPAP years earlier. Finally, the medications of the patients are not clearly stated. We are curious in whether the medication may have had some effect on the results of the study. Did the patients use systemic steroids? What was the dosage of the inhaler drugs? The symptoms may have improved because of medication rather than auto-CPAP.

\section{Compliance with ethical standards}

Conflict of interest The authors declare that they have no competing interests.

Ethical approval All procedures performed in studies involving human participants were in accordance with the ethical standards of the institutional and/or national research committee and with the 1964 Helsinki Declaration and its later amendments or comparable ethical standards.

Informed consent Informed consent was obtained from all individual participants included in the study.

Funding No funding was received for this research.

\section{References}

1. Kauppi P, Bachour P, Maasilta P, Bachour A (2016) Long-term CPAP treatment improves asthma control in patients with asthma and obstructive sleep apnea. Sleep Breath 2016 Apr 7. [Epub ahead of print]

2. Mokhlesi B, Kryger MH, Grunstein RR (2008) Assessment and management of patients with obesity hypoventilation syndrome. Proc Am Thorac Soc 5:218-225 